\title{
Ekonomi Politik Kerja Sama Korea Selatan - Indonesia dalam Joint Development Pesawat Tempur KFX/IFX
}

\author{
Semmy Tyar Armandha, Arwin Datumaya Wahyudi Sumari \& \\ Haryo Budi Rahmadi
}

Universitas Pertahanan Indonesia

\begin{abstract}
ABSTRAK
Proyek kolaborasi pengembangan Korean Fighter Experiment/Indonesian Fighter Experiment (KFX/IFX) Joint Development antara Indonesia dan Korea Selatan dibangun atas dasar keinginan Korea Selatan dan Indonesia untuk membangun kemandirian industri pertahanan di tengah keberadaan negara-negara besar dalam laju pengembangan alat utama sistem persenjataan dunia. Proyek ini pada prosesnya mengalami hambatan dan tarik ulur di antara kedua negara. Tujuan artikel ini adalah untuk menunjukkan bagaimana hambatan tersebut dapat terjadi. Artikel ini menggunakan kerangka teoretis ekonomi kolaborasi dalam proses akusisi pertahanan secara makro. Pendekatan yang digunakan adalah kualitatif untuk menganalisis secara deskriptif relasi Military-Industrial Complex (MIC) dalam proyek KFX/IFX. Hasil yang dicapai dalam penelitian ini adalah pemetaan relasi antara Indonesia-Korea Selatan-Amerika Serikat sebagai segitiga besi pertahanan internasional dalam proyek KFX/IFX.
\end{abstract}

Kata-kata Kunci: ekonomi politik, Kerja Sama Pengembangan KFX/IFX, Military-Industrial Complex, Segitiga Besi Pertahanan

The Korean Fighter Experiment/Indonesian Fighter Experiment KFX/IFX Joint Development is a project between Indonesia and South Korean aimed at fostering the self-reliant defense industry in face of the great power's accelerated major weaponry system build-ups. Since the outset, however, the project has to cope with barriers derived from both the sponsoring governments. This article intends to show the extent to which such barriers have come about, and demonstrates that for one thing the restriction of technology on the part of the great powers. The article employs a macro level economic collaboration theory of defense procurement acquisition combined with a descriptive qualitative approach to discover the aspects of military industrial complex relations in the KFX/IFX project. The finding of the research reveals about an 'iron' triangular international defense relationship existing between Indonesia, South Korea, and the United States in the KFX/IFX project.

Keywords: Defense Iron Triangle, KFX/IFX Joint Development, MilitaryIndustria Complex, political economy 
Abad ke-21 ditandai peningkatan globalisasi industri pertahanan, yang telah menguat sejak tahun 1970-1980an (Kaldor 1998, 2), ditandai tren signifikan intensivitas kerja sama negara-negara di dunia dalam membangun industri pertahanannya (Caverley 2007, 600). Bahkan negara-negara maju sejak saat itu, lebih memilih membangun industrinya melalui kerja sama dengan negara lain dibandingkan melakukannya secara mandiri. Hal ini tidak terlepas dari berbagai tren kebijakan pengetatan anggaran, peningkatan biaya penelitian dan pengembangan, dan peningkatan intensitas persaingan di pasar industri pertahanan (Bitzinger 2009).

Fenomena globalisasi industri pertahanan yang diawali dari belahan dunia Barat (Amerika dan Eropa) juga terjadi di belahan dunia lain. Korea Selatan dan Indonesia adalah dua negara di antaranya. Korea Selatan merupakan salah satu negara non-Atlantik Utara yang memiliki kapabilitas militer yang kuat dan diperhitungkan khususnya di kawasan Asia. Kuatnya pertahanan Korea Selatan menempatkannya dalam peringkat delapan terbesar di dunia dalam hal besarnya armada militer (Weitz 2014). Indonesia dalam hal ini juga merupakan negara yang tengah berupaya membangun kemandirianpembangunan alat utama sistem persenjataan (alutsista), dengan meningkatkan kerja sama dalam prosesnya (Yusgiantoro 2014).

Pada tahun 2010, Indonesia memperoleh ajakan pemerintah Korea Selatan (Korsel) untuk bekerja sama dalam pembuatan pesawat tempur yang mempunyai rentang spesifikasi teknis di antara generasi 4 dan 5 . Proyek pesawat tempur tersebut yang dinamakan dengan Indonesian Fighter Experiment/Korean Fighter Experiment (KFX/IFX).Kerja sama ini dilaksanakan melalui tiga tahap, yaitu Technology Development Phase (TDP), Engineering and Manufacturing Development Phase (EMDP),dan Production Development Phase (PDP) (www.defenseworld.net, 29 Maret 2015).Pada perkembangannya, TDP dibentuk pada tahun 2010 dan selesai pada Desember 2012. Setelah TDP dilaksanakan, pelaksanaan EMDP ditunda hingga tahun 2014. Penundaan tersebut disampaikan oleh parlemen Korsel melalui Defense Acquisition Program Administration (DAPA). Penundaan tersebut berakhir pada September 2014 (www.kemhan.go.id, 6 Maret 2013). Pada bulan Juli 2014, kesepakatan pelaksanaan EMDP dapat tercapai dan direncanakan akan dimulai pada akhir tahun 2015.

Idealnya, negara-negara yang terlibat dalam kerja sama internasional memiliki motivasi biaya (cost (Hartley \& Braddon 2014). Selain itu, transfer teknologi, spin off atau teknologi militer dapat digunakan sebagai teknologi sipil, multiplier effect (efek pengganda) terhadap perekonomian, dan proyeksi akan pengembangan industri pertahanan merupakan manfaat-manfaat yang dapat diperoleh suatu negara dalam kerja sama industri pertahanan. 
Dalam kasus proyek KFX/IFX, tarik ulur yang terjadi antara pemerintah Korea Selatan dan Indonesia, terlihat dari masalah seputar transfer teknologi, pembiayaan, dan spesifikasi. Setidaknya telah terjadi tiga kali penundaan. Penundaan pertama terjadi pada Maret 2013 karena parlemen Korea Selatan yang belum mengizinkan pengucuran dana untuk tahap kedua (www.defenseindustrydaily, 20 Agustus 2015). Penundaan kedua terjadi pada Mei 2015 karena adanya pergantian perdana menteri Korea Selatan, dan hal ini terjadi setelah Indonesia mengucurkan Rp 600 Miliar untuk fase engineering dan manufacturing (www.nasional.harianterbit.com, 20 Agustus 2015), sedangkan penundaan ketiga dilakukan pemerintah Indonesia pada Agustus 2015 dengan batas waktu yang belum dapat ditentukan (www.nasional.tempo.co, 21 September 2015). Hal ini menunjukkan, bahwa dalam perkembangannya akuisisi pertahanan tidak dapat dilepaskan dari relasi ekonomi politik. Relasi tersebut tercipta ketika industri pertahanan sebagai salah satu instrumen pertahanan negara, terlibat dalam relasi antara pemerintah dan parlemen, yang bertambah kompleks seiring dengan semakin pesatnya kerja sama internasional dalam hal pengembangan persenjataan.

Dari kondisi tersebut, tujuan kemandirian industri pertahanan ternyata sangat sulit tercapai, yang memunculkan pertanyaan apakah suatu negara (khususnya Indonesia) dapat benar-benar mandiri. Dari hal tersebut, pertanyaan yang dijawab adalah: bagaimana proses tarik ulur yang terjadi antara Indonesia dan Korea Selatan dalam proyek kolaborasi pengembangan pesawat tempur KFX/IFX tersebut, dalam bingkai relasi ekonomi politik? Dimana letak kondisi yang memungkinkan ketidakmandirian tersebut.Pertanyaan tersebut akan dapat dijawab jika beberapa hal berikut, yang menjadi tujuan artikel ini tercapai. Pertama, dengan mengetahui dinamika akuisisi pertahanan dalam kerja sama pembangunan KFX/IFX, yakni bagaimana proyek akuisisi KFX/IFX menjadi penting untuk dilakukan dan bagaimana tindakan aktor-aktor yang terlibat untuk mewujudkannya. Kedua, dengan mengetahui relasi Military-Industrial Complex (MIC) yang terjadi dalam dinamika akuisisi tersebut. Ketiga,dari dua pemetaan tersebut akan dapat dilihat unsur ekonomi politik dalam proyek ini, terutama dari negara-negara yang terlibat di dalamnya.

Dari beberapa tinjauan literatur yang dilakukan, pemikiran mengenai aspek ekonomi politik dalam pengadaan alat utama persenjataan, mengarah pada argumentasi bahwa kuatnya peran negara maju akan selalu ada dalam upaya negara berkembang dalam membangun kemandirian industri pertahanan. Jonathan Caverley (2007) melihat bahwa Amerika Serikat menciptakan kondisi struktural-hegemonik yang memungkinkan negara-negara bergantung kepada Amerika Serikat (baik secara langsung maupun tidak langsung). Hal ini dilakukan dengan cara mengadakan kerja sama-kerja sama walaupun Amerika 
Serikat dapat secara mandiri mengembangkan sistem persenjataan. Hall dan Coyne (2013) juga melihat bahwa setiap pengadaan yang dilakukan oleh Amerika Serikat akan tertuju pada pencapaian hegemoni global, dengan melihat pada pengadaan drone yang penggunaannya sudah melampaui tujuan awal untuk memberantas terorisme, dimana badan survey McDonald Exum menemukan setiap 1 orang target terbunuh, terdapat 50 orang tidak bersalah yang ikut terbunuh.

Hartemink (2011), Hartley dan Braddon (2014) dengan lebih spesifik melihat fenomena tersebut sebagai hasil dari adanya Military-Industrial Complex; dimana industri, pemerintah, dan regulator (parlemen) memainkan peranan penting dalam setiap pengadaan persenjataan guna menunjang pengembangan industri pertahanan. Hal inilah yang disebut ekonomi politik, dimana proses politik dan proses terbentuknya pasar (mekanisme permintaan-penawaran) bersifat saling mempengaruhi dan mempunyai hubungan timbal-balik yang harus dilihat sebagai aspek yang berimbang. Penjelasan ini yang dapat digunakan untuk mendekati fenomena pengadaan persenjataan, dan akan dirincikan pada kerangka pemikiran berikut.

Artikel ini menggunakan pendekatan kualitatif, yang digunakan untuk mempelajari fenomena secara mendalam (Wahyuni 2012, 11), menganalisis data secara kualitatif atau tidak dapat dinominalkan (Neumann 2008, 61-77). Sumber data bersifat primer dan sekunder. Data primer diambil dengan metode wawancara tidak terstrukur. Data sekunder diambil dari studi literatur dan pemantauan media, yang dilakukan terhadap sumber daring (online), dari situs pencarian Google dengan kata kunci "KFX". Hasil yang didapatkan adalah 131 sumber berita pada rentang waktu Januari 2008 hingga Oktober 2015 terkait isu KFX/IFX, dari media daring di seluruh dunia.

\section{Ekonomi Kolaborasi dalam Proses Akuisisi Pertahanan}

Untuk mengetahui secara sistematis proses dari terbentuknya persepsi ancaman hingga dilakukannya proses pengadaan/akuisisi, Kaldor (1986) menggunakan prinsip permintaan-penawaran yang ada dalam ilmu ekonomi dan ilmu politik. Menurut Kaldor (1986, 577-579) dalam akusisi pertahanan terdapat unsur permintaan (demand) dan penawaran (supply). Agar akuisisi pertahanan terjadi, kedua unsur/aspek tersebut harus bertemu. Bertemunya kedua unsur tersebut dapat terjadi apabila terdapat mekanisme mandat (proxy mechanism) yang dapat berupa perang ataupun peran sistemik di kancah internasional (Kaldor 1986, 579 dan 596). Sebagai contoh dalam kondisi perang, akusisi pertahanan otomatis akan dilakukan karena memang kebutuhan untuk menyerang musuh. Dengan kata lain permintaan dan 
penawaran terjadi karena adanya justifikasi peperangan. Di masa damai, posisi suatu negara dalam kancah internasional mempengaruhi dan menentukan mekanisme mandat tersebut.

James Buchanan berpandangan bahwa negara (dengan dinamika politik di dalamnya) merupakan sumber dari inefisiensi (Hindmoor dalam Hay, et al, 2006, 79-80). Politik dianggap sebagai salah satu faktor kegagalan dalam menciptakan efisiensi (the science of political failure). Hal ini karena pertimbangan pemilihan rekanan tidak didasarkan sepenuhnya pada keunggulan komparatif dan kompetitif serta kriteria-kriteria ekonomis yang objektif. Hal ini justru semakin menunjukkan bahwa faktor politik tidak dapat dikesampingkan meskipun faktor biaya merupakan faktor utama bagi suatu negara untuk mengadakan kerja sama dengan negara lain, khususnya dalam akusisi persenjataan yang sangat mahal harganya jika dibanding dengan produk-produk lain (Hartley \& Braddon, 2014, 535).

Dari kontradiksi tersebut, lahir perspektif ekonomi politik yang mengungkap bahwa akan terjadi Military-Industrial Complex (MIC) dalam suatu kolaborasi. MIC ini yang menjadi gambaran bahwa suatu kolaborasi tidak akan luput dari analisis terhadap faktor-faktor politik, meski secara ideal public choice seharusnya dilandasi oleh pertimbangan atau preferensi efektivitas biaya. MIC merupakan istilah yang diambil dari istilah yang dicetuskan pada tahun 1961 oleh Presiden Amerika Serikat ke-34, Eisenhower, merujuk pada hubungan ekonomi politik yang terjadi antara legislator, angkatan bersenjata nasional, dan industri persenjataan. Hubungan tersebut terkait pada kontribusi politik, persetujuan politik akan belanja militer, lobi-lobi untuk mendukung birokrasi, dan industri (Higgs 1995, 5). Ketiga badan tersebut, yang pada saat ini lebih sering disebut kongres/parlemen, departemen pertahanan, dan industri pertahanan, kemudian disebut sebagai segitiga besi pertahanan (Defense Iron Triangle (DIT)).

Segitiga besi pertahanan merupakan bentuk relasi strategis yang membentuk MIC. Disebut kompleks, karena merujuk pada rumitnya relasi tersebut. Kerumitan yang dimaksud adalah berkaitan dengan seberapa jauh ketiga pihak tersebut membagi proporsi perannya. Jika negara (parlemen dan departmen pertahanan) lebih banyak berpengaruh, maka kedaulatan dan kemandirian lebih ditekankan. Jika industri pertahanan lebih besar perannya, maka aliansi dan kerja sama serta privatisasi (komersialisasi) akan memainkan peranan lebih besar. Meskipun disebut sebagai the unholy trinity (trinitas yang tidak suci) dalam pertahanan (karena peperangan antar negara akan dipengaruhi oleh relasi antara ketiga pihak tersebut), segitiga besi pertahanan penting dalam mewujudkan sebuah akusisi pertahanan, apalagi diahadapkan pada keterlibatan negara lain (Matthews \& Maharani dalam Bitzinger 2009, 38-41). 
Logika utama dalam segitiga besi pertahanan, adalah bahwa industri memiliki relasi konstituen dengan para legislator (anggota parlemen) agar mendapat dukungan legislasi, dan sebaliknya parlemen memiliki kepentingan agar dipilih kembali; sedangkan pemerintah membutuhkan dukungan industri dan parlemen agar program kerja dapat didukung dengan anggaran dan teknologi (Noll, 1971, 1-10). Dari gambar segitiga besi tersebut dapat dilihat bahwa relasi ketiganya sangat penting dalam mewujudkan kapabilitas militer yang diperlukan, melalui proses akuisisi pertahanan.

\section{Sejarah Proyek KFX/IFX}

Kesepakatan kerja sama antara Korea Selatan dan Indonesia dibentuk dengan berlandaskan hubungan diplomatik yang telah terjalin sejak 17 September 1973 (http://www.mofa.go.kr, 15 November 2015). Namun kerja sama komprehensif baru disepakati pada Desember 2006, dimana Kepala Negara Indonesia dan Korea Selatan menandatangani sebuah perjanjian Kemitraan Strategis; Joint Declaration on Strategic Partnership to Promote Friendship and Cooperation in the 21st Century (http://www.mofa.go.kr, 15 November 2015). Isi dari kesepakatan tersebut adalah dibentuknya The Eminent Persons Group (EPG) yang berisi kerja sama di bidang perdagangan dan investasi; kehutanan; nuclear power plant; teknologi industri kecil dan menengah; antikorupsi; pertahanan dan keamanan; pusat kebudayaan; dan pariwisata.

Atas dasar klausul inilah Indonesia menerima ajakan Korea Selatan untuk mengembangkan secara bersama Proyek Boramae untuk mengembangkan Fighter Experiment. Menteri Pertahanan Republik Indonesia Purnomo Yusgiantoro meyakinkan publik bahwa pilihan untuk bekerja sama dengan Korea Selatan sangat tepat untuk mengembangkan industri pertahanan (Amperiawan, wawancara 17 November 2015). Purnomo melihat bahwa Korea Selatan bersedia untuk memindahkan teknologinya, sehingga Indonesia akan mampu memiliki dan mengembangkan teknologi sendiri khususnya dalam teknologi pesawat tempur (www.nasional.tempo.co, 15 November 2015).

Kim Dae-jung merupakan Presiden Korea Selatan yang pertama kali menggagas dibangunnya pesawat tempur orisinil tersebut pada 2001, setelah Agency for Defense and Development (ADD) pada tahun 1999 menyelesaikan penelitian di bidang aeronautica dan aerospace untuk kemungkinan membuat pesawat tempur pribumi (orisinil) (www.aviationweek.com, 28 September 2015). Pada awal perencanaannya, pesawat tempur ini ditargetkan akan selesai pada tahun 2020 dengan jumlah 120 pesawat. Dengan desain satu pilot (single seat), mesin ganda (twin engine), KFX direncanakan memiliki 
kemampuan stealth (tak terdeteksi radar) di atas level Eurofighter Typhoon dan Dassault's Rafale, namun masih di bawah F-35 Joint Strike Fighter(JSF).

\section{Proses Akusisi Pertahanan KFX/IFX}

Penjelasan akuisisi pertahanan yang fokus pada faktor eksternal disebut sebagai aspek permintaan, sedangkan yang berfokus pada faktor internal adalah upaya untuk memenuhi permintaan tersebut dengan penawaran. Penjelasan aspek permintaan (demand) dapat dibagi kembali menjadi dua aspek, yakni aspek sistemik dan aspek institusional. Aspek sistemik adalah persepsi ancaman yang ditentukan dari situasi internasional baik yang terkait secara langsung maupun tidak langsung. Setelah ancaman tersebut didefinisikan oleh angkatan bersenjata, birokrasi pemerintah, dan parlemen, maka aspek tersebut dinamakan aspek institusional. Penjelasan aspek penawaran (supply) dapat dijabarkan ke dalam aspek penemuan, inovasi, dan integrasi. Teknologi dapat muncul pada tahap penemuan, kemudian diproduksi oleh industri sebagai tahap inovasi, dan terakhir diintegrasikan dalam operasional matra-matra militer. Kedua penjelasan aspek ini akan menjadi fokus dalam penjelasan proses akusisi pertahanan KFX/IFX.

Aspek sistemik yang menjadi landasan munculnya proyek KFX berasal dari keinginan Korea Selatan untuk membangun pesawat tempur pribumi dengan kemampuan stealth yang tinggi guna menghadapi kekuatan tempur Korea Utara yang seringkali mengancam. Korea Utara dan Korea Selatan hingga kini masih dalam kondisi berperang. Puncaknya, serangan Korea Utara ke Pulau Yeonpyeong pada 2010 menambah urgensi dikembangkannya pesawat tempur KFX tersebut. Oleh karenanya, program transformasi militer yang digiatkan oleh Korea Selatan dibangun untuk menyesuaikan ancaman dari Korea Utara, yang selama ini membangun pertahanan militernya lebih besar dari Korea Selatan (Tan 2011, 79-80).

Upaya membangun "self-defense" (pertahanan diri) dapat dikategorikan sebagai aspek institusional karena berkaitan dengan respon internal Korea Selatan terhadap kondisi sistemik eksternal yang mengelilinginya. Proyek KFX dapat dikatakan sebagai salah satu dari respon internal Korea Selatan, karena melalui proyek tersebut Korea Selatan bercita-cita memiliki pesawat tempur buatan lokal (Bae 2003, 75). Upaya mewujudkan kemandirian tersebut terus dilakukan pada awal 1990-an hingga kini. Ancaman Korea Utara masih menjadi kekhawatiran, namun meningkatnya kekuatan militer Tiongkok dan Jepang, yang mana menambah dilema keamanan di Asia Timur, turut menjadi salah satu 
ancaman bagi kedaulatan Korea Selatan (www.add.re.kr, 17 November 2015).

Di sisi Indonesia, terdapat tiga motivasi utama dalam menerima tawaran Korea Selatan untuk bekerja sama dalam pengembangan ini (E. Heryanto, wawancara, 4 Agustus 2015). Pertama, untuk membangun kemandirian di bidang pertahanan. Indonesia telah mengalami berbagai embargo dari negara-negara Barat, sehingga dapat dikatakan memiliki uang (untuk membeli senjata) belum tentu dapat menggunakannya secara leluasa. Kedua, adalah motivasi teknologi, dimana Indonesia masih sangat minim dalam hal teknologi pertahanan. Pengembangan bersama ini diharapkan dapat memungkinkan transfer teknologi ke Indonesia. Ketiga, adalah kontribusi terhadap perekonomian. Proyek dengan anggaran sebesar KFX dapat memberikan efek pengganda pada perekonomian, yang diharapkan dapat semaju Amerika Serikat yang sudah mengandalkan industri sektor pertahanannya.

Ketiga motivasi utama tersebut memiliki latar belakang historis, yakni bahwa Indonesia pernah mengalami sejarah kelam rezim otoritarian militeristik. Hingga saat ini, Indonesia masih bergulat pada upaya reformasi militer guna beradaptasi dengan sistem demokrasi (Sebastian \& Gindarsah 2013, h. 293). Demokrasi sendiri telah memungkinkan banyaknya tekanan terhadap organisasi militer untuk menyerahkan sepenuhnya persoalan politik kepada sipil, dan militer harus menjadi tenaga profesional murni seutuhnya guna melindungi teritorial kedaulatan Negara Kesatuan Republik Indonesia (NKRI).

Dalam aspek penawaran, proyek KFX/IFX telah melalui satu tahap yakni tahap penemuan, yang disebut dalam proyek ini sebagai fase pengembangan teknologi (Technology Development Phase). Adapun tahap inovasi dalam proyek ini disebut sebagai fase rekayasa dan manufaktur (Engineering and Manufacturing Development Phase), dimana pada tahap ini akan dibuat purwarupa pesawat untuk diuji coba kelaikannya. Tahap integrasi dalam proyek ini disebut fase produksi dan pemasaran (Production Phase \& Marketing Phase), dimana pesawat akan diproduksi masal dan dipasarkan (Kusmiyati, wawancara 5 September 2015).

Nota kesepahaman (Memorandum of Understanding (MoU)) antara Kementerian Pertahanan Republik Indonesia dan Kementerian Pertahanan Nasional Republik Korea ditandatangani pada 15 Juli 2010. MoU tersebut berisikan kesepakatan mengenai pengembangan bersama berikut dengan penelitian, produksi, dan pemasaran bersama antara Korea Selatan dan Indonesia untuk membangun pesawat tempur Korea (KFX) dengan kemampuan multi-role generasi ke 4,5. Adapun Korea Selatan akan menanggung $80 \%$ dan Indonesia 20\% dari biaya keseluruhan. 
Dalam membangun KFX/IFX, Pemerintah Republik Korea menggandeng Korean Aerospace Industry (KAI) sebagai kontraktor. KAI terpilih sebagai satu-satunya perusahaan yang mampu memenuhi ketentuan dari pemerintah mengalahkan Korean Airlines (KAL) (Giyoung, wawancara 11 September 2015). KAI menggandeng perusahaan alutsista asal Amerika Serikat yakni Lockheed Martin. Peranan Lockheed Martin adalah sebagai sumber transfer teknologi yang dibutuhkan bagi pengembangan KFX/IFX. Pesawat yang akan dihasilkan dari proyek KFX/IFX merupakan kelanjutan dari T-50 Golden Eagle, yakni pesawat yang dikembangkan oleh Korea Selatan dan Amerika Serikat. Selain itu, Korea Selatan memiliki perjanjian offset dengan Amerika Serikat dalam pembelian pesawat tempur paling mutakhir abad ini yaitu F-35 JSF. Dari offset ini, diharapkan 25 teknologi yang telah berhasil diimplementasikan pada F-35 JSF dapat diaplikasikan ke dalam pesawat hasil dari proyek KFX/IFX.

\section{Gambar 1. Akusisi Pertahanan KFX/IFX dari Aspek Permintaan dan Penawaran}

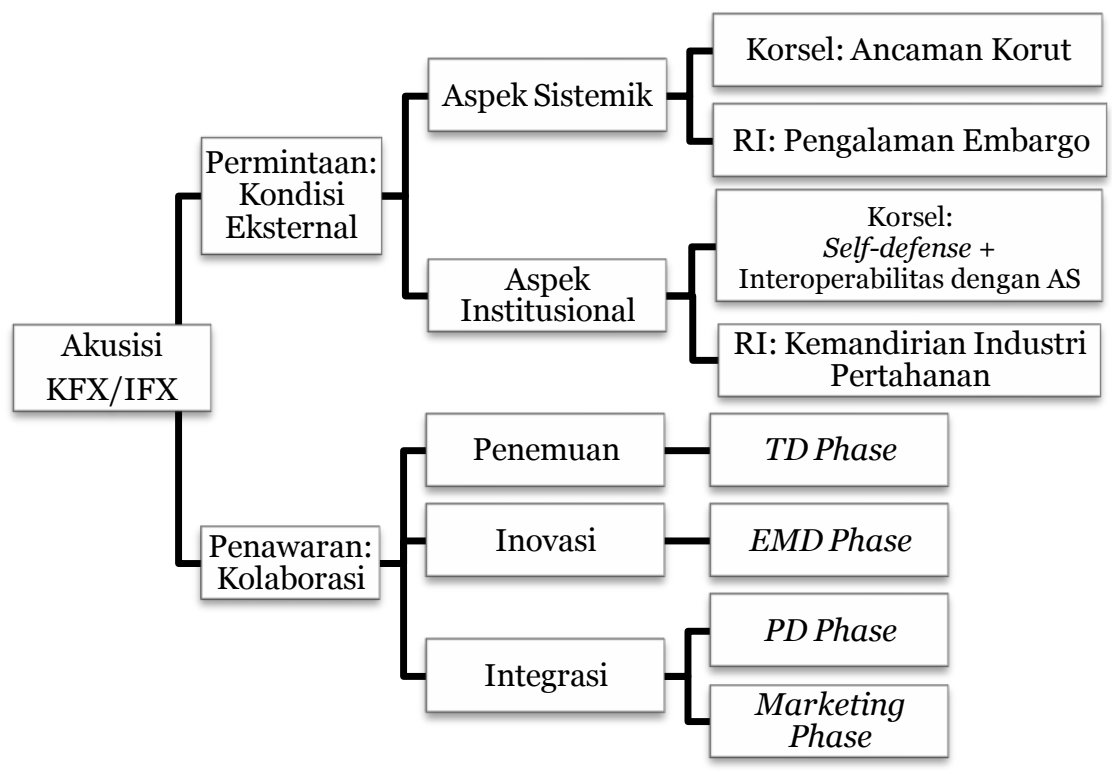

(Sumber: Diolah Penulis)

Gambar 1 merupakan ilustrasi bertemunya aspek permintaan dan penawaran yang telah dijabarkan sebelumnya. Aspek permintaan yang telah terbentuk dari kondisi-kondisi eksternal baik dari Korea Selatan maupun Indonesia, diantisipasi dengan aspek penawaran yang berupa kolaborasi. 


\section{Military-Industrial Complex Proyek KFX/IFX}

Dalam proyek pengembangan KFX/IFX, terdapat sederet motivasi ekonomi dan politik baik Korea Selatan dan Indonesia yang masingmasing telah dijabarkan sebelumnya. Namun motivasi tersebut masih berdiri masing-masing dengan kepentingan nasionalnya masing-masing pula, sehingga masih belum terlihat relasi strategis antara Korea Selatan dan Indonesia. Sebelum jauh melihat relasi strategis tersebut, bagan dalam gambar 2 berikut akan memperlihatkan aktor-aktor kunci dalam kerja sama pengembangan KFX/IFX.

\section{Gambar 2. Aktor-aktor yang terlibat dalam Proyek KFX/IFX}

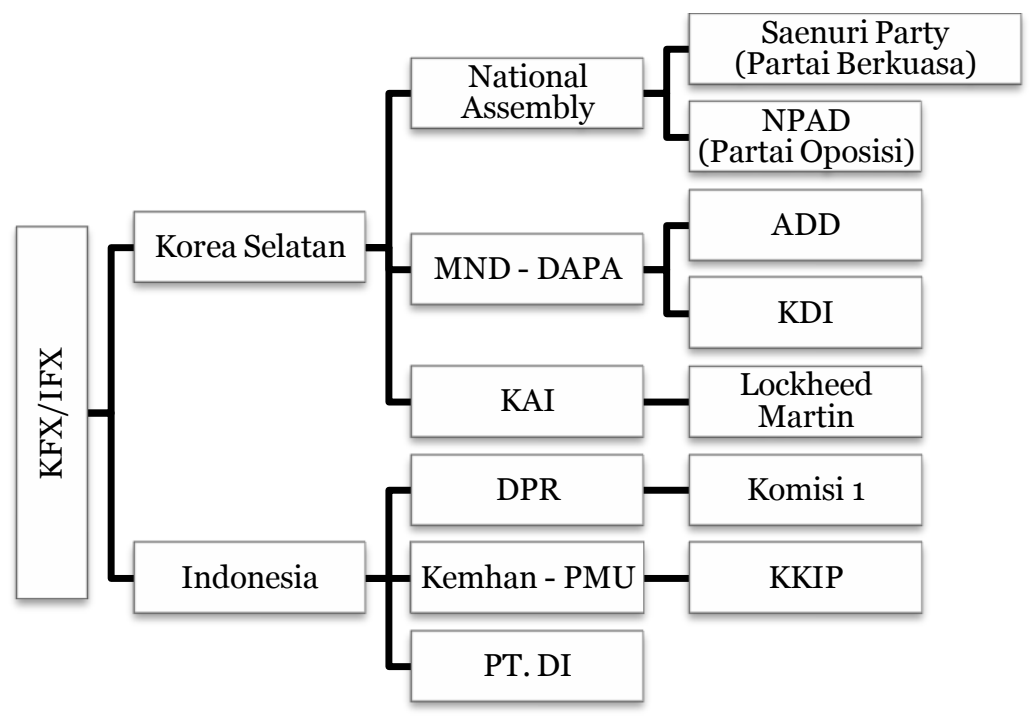

(Sumber: Diolah Penulis)

Dari Gambar 2, terlihat bahwa dalam proyek KFX/IFX tidak hanya terkait dua negara Korea Selatan dan Indonesia saja melainkan Amerika Serikat turut andil. Dalam penjabaran aspek permintaan proyek KFX/IFX, telah disinggung bahwa Amerika Serikat merupakan negara yang paling besar pengaruhnya terhadap Korea Selatan terutama dalam bidang pertahanan. Hal ini menjadikan Amerika Serikat masuk dalam area MIC dalam proyek KFX/IFX.

Meskipun Amerika Serikat memang tidak secara langsung berkepentingan dalam proyek ini, namun salah satu perusahaan pengembang persenjataannya yakni Lockheed Martin memiliki relasi dengan KAI sebagai kontraktor KFX/IFX. Korea Selatan membeli 40 pesawat tempur F-35 dengan fasilitas offset, yakni akan mendapatkan 25 teknologi F-35. 25 teknologi ini akan diadopsi ke dalam pesawat F-33 hasil dari proyek KFX/IFX. Selain itu, perusahaan pengembang 
persenjataan lain seperti Boeing dan General Dynamic juga pernah berminat untuk bekerja sama dengan KAI dan menjanjikan transfer teknologi seperti halnya Lockheed Martin. Namun Boeing yang menawarkan transfer teknologi pesawat tempur F-15 tidak berhasil terpilih bersamaan dengan penggandengnya yakni KAL, sedangkan General Dynamic tidak mampu menyaingi citra Lockheed Martin yang berhasil mengembangkan F-35.

Dari sisi Korea Selatan, badan yang dipercaya untuk mengepalai berlangsungnya proyek ini adalah DAPA. Agen yang dibentuk pada 1 Januari 2006 ini, ditugaskan oleh Kementerian Pertahanan Nasional Korea Selatan dalam urusan-urusan akusisi dan pengadaan persenjataan, serta pengembangan industri pertahanan (www.dapa.go.kr, 22 November 2015). DAPA bertanggung jawab atas pengembangan dan pengadaan persenjataan setelah pihak militer memberikan proposal kebutuhannya. Dalam hal ini DAPA mencakup semua proses; dari penelitian dan pengembangan, penyusunan estimasi anggaran, pembelian, hingga uji coba. Proses produksi massal setelahnya menjadi tanggung jawab Kementerian Pertahanan Nasional.

Dalam konteks penelitian dan pengembangan yang tidak dapat dilakukan secara mandiri oleh DAPA, dilakukan proses yang disebut Request for Proposal (RFP) untuk mencari perusahaan mana yang tertarik untuk menjadi kontraktor. Kolonel Lee Jong-hee, Direktur Pengembangan DAPA pada Juli 2010 menjelaskan bahwa banyak pihak yang tertarik untuk berinvestasi dalam proyek KFX/IFX (www.defensenews.com, 24 Oktober 2015). Hal tersebut ternyata juga terkait dengan program F-XIII Korea Selatan. Program F-XIII berisi rencana akuisisi besar-besaran untuk memperbarui skuadron pesawat tempur Korea Selatan ke tingkat generasi yang lebih mutakhir. Perusahaan-perusahaan yang tertarik di antaranya Boeing dan Lockheed Martin dari Amerika Serika, EADS dari Uni Eropa, dan Saab dari Swedia. Korea Selatan juga sempat menawarkan RFP pada Turki, namun Turki menolak dan akhirnya diberikan kepada Lockheed Martin yang digandeng oleh KAI sebagai rekanan kontraktor (P. Hutabarat, wawancara, 25 Agustus 2015).

Dalam urusan penelitian awal dalam rangka mengembangkan teknologi pertahanan, DAPA juga dibantu oleh Agency for Defense Development (ADD) dan Korean Development Institute (KDI) (www.add.go.kr, 22 November 2015). Kedua badan tersebut pada tahun 1970 dan 1971 sebagai lembaga think tank Korea Selatan di bidang pertahanan, pembangunan ekonomi dan sosial.

Di pihak Indonesia, PT. Dirgantara Indonesia (DI) didaulat sebagai kontraktor untuk menangani KFX/IFX. PT. DI merupakan satu-satunya industri pesawat terbang di Indonesia, dan berdiri sejak April 1976. PT. 
DI pernah membangun pesawat $\mathrm{CN}-235$, berkolaborasi dengan European Aeronautic Defense and Space Company CASA (EADSCASA) dari Spanyol (Bitzinger, 2009, h. 345). PT. DI banyak terlibat sebagai sub-kontraktor dengan industri dirgantara besar di dunia seperti Boeing, Airbus, General Dynamic, Fokker, dan lain sebagainya. Namun PT. DI belum pernah sekalipun membangun pesawat jet tempur. Hal ini yang membuat proyek KFX/IFX dipandang sebagai awal bagi upaya kemandirian industri pertahanan, khususnya di bidang kedirgantaraan.

Selain aktor pemerintah dan industri, parlemen juga memainkan peranan penting. Di sisi Korea Selatan, adalah National Assembly yang merupakan nama dari aktor parlemen, sedangkan di sisi Indonesia adalah Dewan Perwakilan Rakyat (DPR). Peranan parlemen di kedua negara relatif sama, yakni sebagai penentu besaran anggaran yang akan dikeluarkan bagi pemerintah. Selain itu, parlemen dapat mengajukan pertanyaan kepada pemerintah terkait proyek, termasuk meminta dilakukannya peninjauan ulang terhadap proyek tersebut. Kekuasaan parlemen terletak pada fungsi anggaran, dan pada fungsi pengawasan terhadap penggunaan anggaran tersebut.

Di sisi Korea Selatan terdapat dua partai besar yang menduduki posisi di National Assembly yakni partai berkuasa Saenuri dan partai oposisi New Politics Alliance for Democracy (NPAD), sedangkan di Indonesia terdapat Komisi 1 yang mewakili DPR. Korea Selatan menganut sistem demokrasi parlementer, sedangkan Indonesia mengantu sistem demokrasi presidensil. Oleh karenanya Indonesia tidak mengenal sistem partai berkuasa dan oposisi.

Setelah menjabarkan tentang aktor-aktor,selanjutya adalah menggambarkan segitiga besi pertahanan yang berperan dalam proyek KFX/IFX. Segitiga besi pertahanan merupakan konsep yang lebih spesifik dari MIC, karena sudah menjelaskan aktor-aktor yang terlibat serta relasi antara aktor tersebut. Terkait dengan hal tersebut, berdasarkan penjabaran aspek permintaan dan penawaran proyek KFX/IFX, dapat disimpulkan terdapat tiga negara yang punya andil besar dalam proyek tersebut, yakni Korea Selatan, Indonesia, dan Amerika Serikat yang ilustrasinya ditunjukkan dalam Gambar 3.

Gambar 3 menunjukkan relasi MIC yang dikategorikan dalam aspek permintaan (demand) dalam proyek KFX/IFX. Dari gambar tersebut, telah dijabarkan adanya irisan di semua aktor, dengan irisan paling tengahnya menjadikan KFX/IFX seagai titik temu antara ketiga aktor. Keseluruhan relasi tersebut sudah dijabarkan pada bagian proses akuisisi pertahanan, yakni pada bagian aspek permintaan. Ketiga aktor yang berada dalam lingkaran diagram venn tersebut, adalah yang mewujudkan akuisisi pertahanan hingga tahap proses pengadaan. 


\section{Gambar 3. Segitiga Besi Pertahanan Proyek KFX/IFX dalam aspek penawaran}

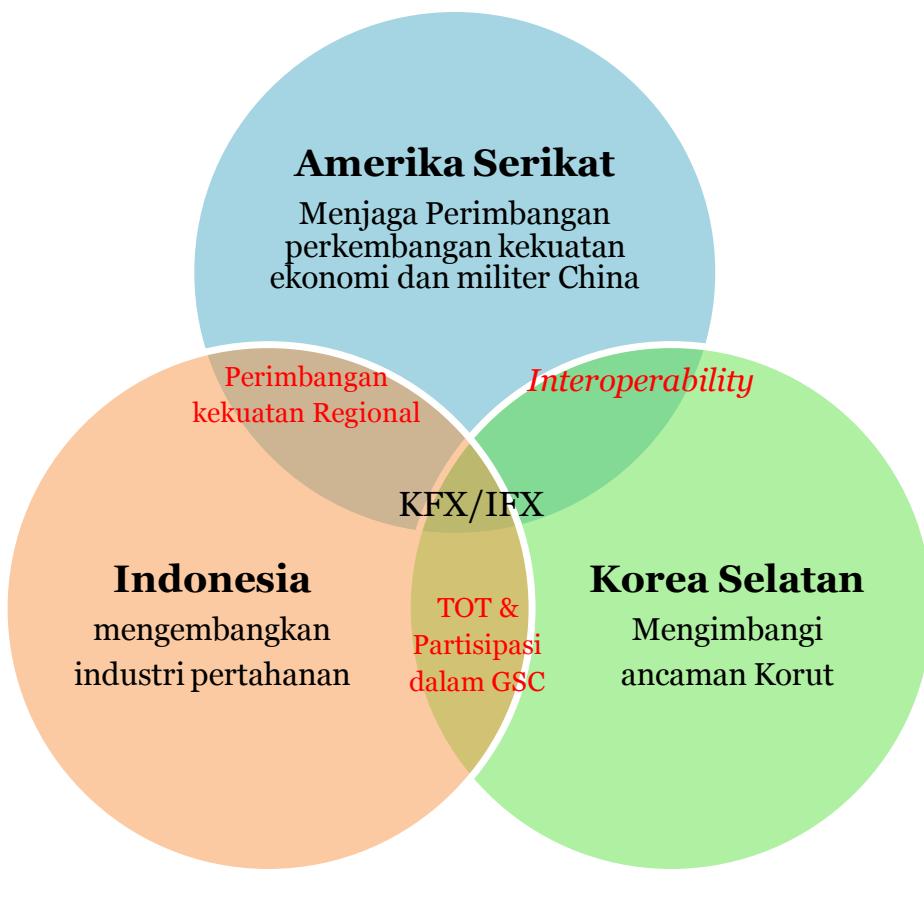

(Sumber: Diolah Penulis)

Gambar di atas merupakan relasi MIC yang dikategorikan dalam aspek permintaan (demand) dalam proyek KFX/IFX. Dari gambar tersebut, telah dijabarkan adanya irisan di semua aktor, dengan irisan paling tengahnya menjadikan KFX/IFX sebagai titik temu antara ketiga aktor. Keseluruhan relasi tersebut sudah dijabarkan pada bagian proses akuisisi pertahanan, yakni pada bagian aspek permintaan. Aspek penawaran, yang merupakan respons dari aspek permintaan, dapat dilihat pada Gambar 4. Ketiga aktor yang berada dalam lingkaran diagram venn tersebut, adalah yang mewujudkan akuisisi pertahanan hingga tahap proses pengadaan. 


\section{Gambar 4. Segitiga Besi Pertahanan dalam Aspek Penawaran}

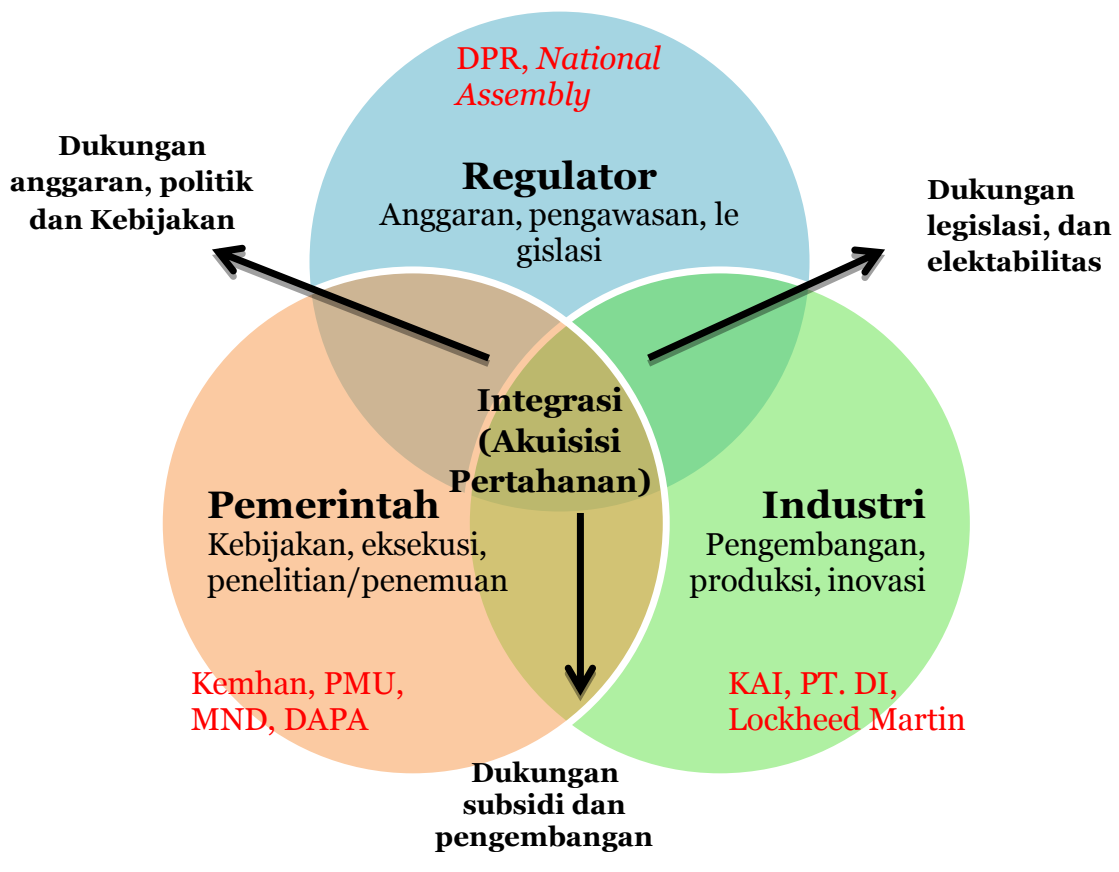

(Sumber: Diolah Penulis)

Berdasarkan pemetaan yang telah dilakukan, terdapat tiga hal yang dapat disarikan dari aspek ekonomi politik dalam proyek KFX/IFX. Pertama, gambaran data hasil penelitian telah menunjukkan bahwa segitiga besi pertahanan bukanlah lagi soal segitiga besi pertahanan Indonesia saja ataupun Korea Selatan saja. Korea Selatan-IndonesiaAmerika Serikat dalam proyek KFX/IFX dapat dikatakan membentuk suatu relasi strategis segitiga besi pertahanan internasional (international DIT). Hal ini dapat ditunjukkan dari hasil pemantauan media terkait proyek KFX/IFX di situs pencarian Google, yang dapat ditunjukkan dalam Gambar 5. 


\section{Gambar 5. Persentase Pernyataan dari media daring terkait proyek kolaborasi KFX/IFX berdasarkan asal negara}
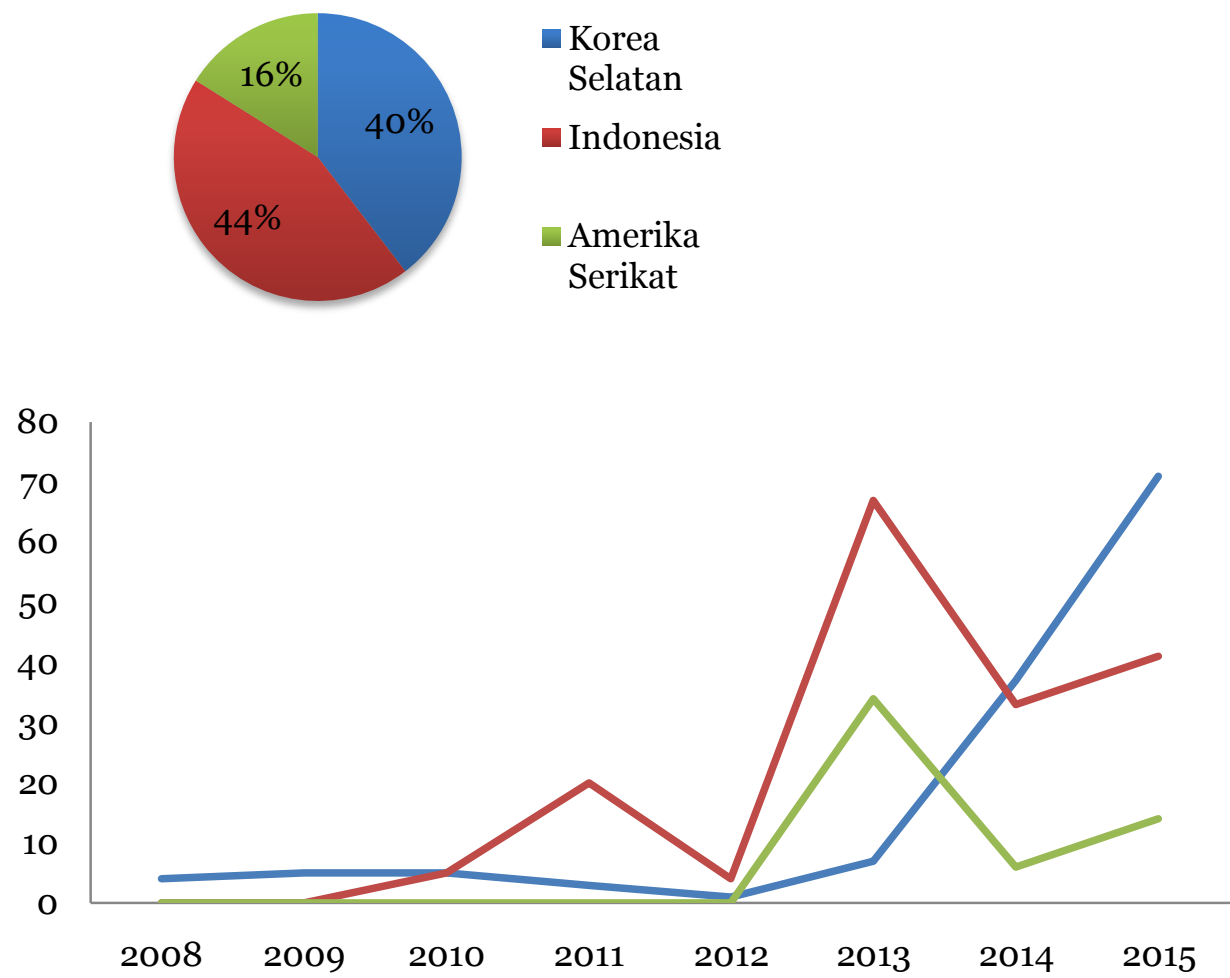

(Sumber: diolah penulis)

Gambar 5 merupakan data hasil pemantauan media yang dikumpulkan dari Januari 2008 hingga Oktober 2015, menunjukkan pernyataanpernyataan pihak-pihak yang berkepentingan dalam proyek kolaborasi KFX/IFX, berasal dari tiga negara yakni Indonesia, Korea Selatan dan Amerika Serikat. Hal ini sesuai dengan pihak-pihak yang memang pada pemetaan (aktor-aktor) sebelumnya, berkepentingan dalam proyek tersebut. Dalam hal ini dapat dilihat bahwa pihak-pihak dari Indonesia paling banyak mengeluarkan pernyataan, diikuti oleh Korea Selatan dan Amerika Serikat.

Analisis tersebut telah dipetakan relasi antara ketiga negara. Posisi Amerika Serikat yang bertindak sebagaimana regulator dalam segitiga besi pertahanan: tidak terlibat langsung dalam program apapun namun memiliki andil dalam menentukan dinamika program. Korea Selatan bertindak sebagai agensi pemerintah, sebagai pihak yang memimpin jalannya program dan memiliki kepentingan paling besar, namun tetap membutuhkan dukungan baik politik dari parlemen maupun kinerja 
dari industri. Indonesia bertindak sebagaimana kelompok kepentingan (dalam hal ini industri): membutuhkan anggaran dan proyek agar ekonomi dapat berjalan.

Dalam skema MIC KFX/IFX, Amerika Serikat merupakan aktor yang paling tidak berkepentingan, namun memiliki pengaruh yang besar terhadap keberlangsungan proyek KFX/IFX. Amerika Serikat tidak memiliki andil dalam cost share dan work share, dan juga tidak terlibat dalam JPMO, namun embrio KFX/IFX berasal dari Amerika Serikat. Pesawat T-50 Golden Eagle hasil pengembangan kolaborasi Amerika Serikat dan Korea Selatan adalah yang digunakan sebagai kerangka awal. Selain itu, Korea Selatan telah sepakat membeli 40 pesawat F-35 dengan fasilitas perjanjian offset 25 teknologi untuk diadaptasi KFX/IFX. Hal tersebut membuat posisi Amerika Serikat cukup krusial di samping ikatan aliansi yang kuat dengan Korea Selatan.

Kedua, bahwa mekanisme bertemunya permintaan dan penawaran bersandar pada pemahaman ketiganya mengenai tata dunia (world order). Dari pemahaman tata dunia tersebut, terdapat turunan lain persepsi mengenai keamanan internasional yang menurunkan persepsi ancaman. Bertemunya permintaan dan penawaran membutuhkan apa yang disebut Kaldor sebagai mekanisme mandat (Kaldor 1986, 579 dan 595). Amerika Serikat memiliki kepentingan untuk menstabilkan perimbangan kekuatan di kawasan Asia Pasifik terutama di Asia Timur yang persaingannya tinggi(www.diplomat.com, 26 Oktober 2015).

Dari pemantauan media yang dilakukan, pada tahun 2013 pihak Lockheed Martin terus melakukan lobi dan pendekatan untuk meyakinkan DAPA bahwa transfer teknologi siap dilakukan demi mendukung proyek KFX/IFX. Hal tersebut gencar dilakukan di tengah semakin banyaknya tawaran dari Uni Eropa untuk menggantikan Lockheed Martin sebagai rekanan.

Pendekatan Lockheed Martin berhenti ketika pada 31 Maret 2015 terpilih bersama dengan KAI untuk mengemban proyek KFX/IFX. DAPA mengadakan RFP untuk menentukan kontraktor KFX/IFX pada 23 Desember 2014 dengan tenggat waktu hingga 9 Februari 2015 (www.spacedaily.com, 22 Oktober 2015). Dari tenggat waktu yang disediakan tersebut, hanya KAI yang mampu menyelesaikan dengan tepat waktu seluruh persyaratan. Namun regulasi di Korea Selatan mengharuskan paling tidak terdapat dua kandidat dalam suatu tender proyek pengadaan, sehingga tenggat waktu diperpanjang hingga 24 Februari. Hingga waktu yang diperpanjang tersebut KAL masih belum dapat merampungkan persyaratan dengan alasan kurangnya persiapan. Pada akhirnya KAI dipilih dengan seizin parlemen karena ketiadaan kandidat lain. 
Pada tahun 2015 terlihat pemerintah Amerika Serikat baru merespon terhadap Korea Selatan, karena terkait batalnya transfer empat teknologi utama F-35 (Kode: AS-Govt-Diplo). Polemik terjadi manakala DAPA baru melaporkan kepada publik Korea Selatan bahwa Amerika Serikat menolak transfer empat teknologi utama F-35 pada April 2015. Pada September 2015, Amerika Serikat mengumumkan kembali mengenai penolakan atas transfer teknologi tersebut. Merespon hal tersebut, pada Oktober 2015, Park Geun-hye melakukan serangkaian kunjungan diplomatik ke Amerika Serikat untuk membicarakan kelanjutan aliansi. Dalam pertemuan tersebut, Amerika Serikat berjanji akan membuat forum khusus untuk menegosiasikan transfer teknologi terkait dengan KFX/IFX.

Ketiga, fakta bahwa Indonesia semakin berkepentingan dalam rantai pasokan global menunjukkan bahwa Indonesia sedang beradaptasi dalam perubahan yang sarat akan globalisasi industri pertahanan (Yusgiantoro 2014). Hal ini bagai gayung bersambut dengan program "self-defense" Korea Selatan. Konteks Korea Selatan mengajak Indonesia untuk bergabung dalam proyek KFX, adalah bahwa Korea Selatan sedang berupaya menciptakan 'kawan' yang level kemajuannya masih di bawah mereka sambil mencari pasar bagi jual-beli persenjataan mereka (Weitz dalam Hamisevicz, 2014, 49-50).

\section{Simpulan}

Proyek Kerja Sama Pengembangan KFX/IFX antara Korea Selatan dan Indonesia, membentuk relasi segitiga besi pertahanan internasional yang tidak dapat dilepaskan dari peranan dan kepentingan Amerika Serikat. Pengaruh negara maju dengan kekuatan besar masih belum dapat dilepaskan dari upaya kemandirian industri pertahanan di negara berkembang. MIC menjadi suatu kondisi yang niscaya dalam setiap pengadaan alat pertahanan, dan kerja sama antar negara memungkinkan lebih dalamnya pengaruh negara maju terhadap negara berkembang tersebut.Hal tersebut dapat dilihat dari dinamika proses akuisisi pertahanan yang melandasi terbentuknya kerja sama pengembangan KFX/IFX antara Korea Selatan dan Indonesia.Dari penelusuran aspek permintaan dan penawaran, dapat dilihat proxy mechanism yang menyatukan antara keduanya. Keinginan Korea Selatan untuk memperkuat barisan pesawat tempurnya, dengan pertimbangan ancaman Korea Utara dan pengurangan ketergantungan terhadap Amerika Serikat, menjadi landasan yang kuat dalam menciptakan proyek KFX/IFX. Keinginan ini bagai gayung bersambut ketika Indonesia dipilih sebagai rekanan dalam membangun pesawat tempur tersebut. Indonesia merupakan salah satu negara yang memiliki banyak investasi Korea Selatan dan telah banyak membeli alutsista 
Korea Selatan. Indonesia sendiri memiliki pengalaman buruk embargo senjata dari Amerika Serikat, sehingga memiliki keinginan kuat akan pengembangan industri pertahanan.

Pemetaan segitiga besi pertahanan menunjukkan adanya relasi kompleks-strategis yang mau tidak mau harus dihadapi Indonesia ke depan dalam proyek KFX/IFX. Dari pemetaan tersebut, terlihat adanya segitiga besi pertahanan internasional. Amerika Serikat cenderung berperan sebagai regulator, yang tidak memiliki kepentingan langsung namun memiliki pengaruh kuat dan menentukan laju perkembangan proyek (dengan penguasaan teknologinya). Korea Selatan cenderung berperan sebagai agensi pemerintah yang memiliki kepentingan paling besar (80\% investasi) dalam proyek. Indonesia, dalam hal ini cenderung terlihat sebagai kontraktor: tidak memiliki kepentingan yang cukup besar (20\% investasi), dan sangat bergantung pada dinamika hubungan antara Korea Selatan dan Amerika Serikat.

Saran yang dapat diberikan dari pemetaan ini, adalah: (1) Untuk Kementerian Pertahanan: agar meningkatkan pemanfaatan parlemen (DPR) sebagai pengawas penggunaan anggaran. Penundaan yang dilakukan Korea Selatan dapat dihindari terulang lagi jika parlemen turut "berbicara" bersama pemerintah. Jika parlemen juga mendukung dengan positif, maka segitiga besi pertahanan Indonesia akan lengkap dan kokoh; (2) Untuk DPR, agar lebih kritis pada pelaksanaan proyek KFX/IFX. Hal ini dengan jelas ditunjukkan oleh Partai Saenuri dan NPAD dalam National Assembly di Korea Selatan ketika mengetahui gagalnya transfer teknologi F-35. Kritisnya parlemen akan menunjukkan kuatnya check and balances dalam suatu negara; (3) Untuk Industri pertahanan khususnya PT. Dirgantara Indonesia: agar dapat memaksimalkan peran pemerintah dan pro-aktif dalam mendukung pengembangan industri pertahanan. Di sisi lain pemerintah juga harus pro-aktif mencari dan menemukan pasar internasional dan memberikan dukungan anggaran.

\section{Daftar Pustaka}

\section{Buku}

Bitzinger, Richard A., 2009. The Modern Defense Industry: Political, Economic, and Technological Issues. California: ABC CLIO.

Brooks, Stephen G., 2005. Producing Security: Multinational Corporations, Globalizations, and the Changing Calculus of Conflict. Princeton: Princeton University Press. 
Brymann, Alan, dan Robert G. Burgess, 1994. Analyzing Qualitative Data. London \& New York: Routledge.

Buszynski, Leszek, 2013. Negotiating with North Korea: The Six Party Talks and the Nuclear Issue. London \& New York: Routledge.

Hamisevicz, 2014. On Korea 2014: Academic Paper Series Volume 7. Washington DC: Korea Economic Institute of America.

International Institute for Strategic Studies, 2015. The Military Balance 2015: The Annual Assesment of Global Military Capabilities and Defense Economics. IISS

Kaldor, Mary. dan Ulrich Albrecht., 1998. The End of Military Fordism: Restructuring the Global Military Sector. London: United Nations University

Klotz, Audie dan Deepa Parkash, 2008. Qualitative Methods in International Relations: A Prularist Guide. New York: Palgrave McMillan.

Kuntjoro-Jakti, Dorodjatun, 2012. Menerawang Indonesia Pada Dasawarsa Ketiga Abad Ke-21. Jakarta: Pustaka Alvabet.

McNally, David., 2011. Global Slump: The Economics and Politics of Crisis and Resistance. Oakland: PM Press.

Miller, Raymond C., 2008. International Political Economy: Contrasting World Views. London dan New York: Routledge Taylor and Francis

Noll, Roger G., 1971. Reforming Regulation: An Evaluation of the Ash Council proposals. Washington DC: Brookings Institution.

Sandler, Todd. dan Hartley, Keith., 1995. Handbook of Defense Economics: Defense in a Globalized World, Vol. 2. New York: Elsevier Science.

Singh, Rajab P,, et al., 1998. Arms Procurement Decision Making, Volume I: China, India, Israel, Japan, South Korea, and Thailand. Oxford: Oxford University Press.

Sorensen, D.S., 2009. The Process and Politics of Defense Acquisition: A Reference Handbook. London: Praeger Security International.

Wahyuni, Sari, 2011. Metodologi Penelitian Kualitatif. Jakarta: Salemba Empat.

Walliman, Nicholas, 2001. Your Research Project: A Step-b- Step guide for The First-time Researcher. London: Sage Publications.

\section{Jurnal}

Bae, Jun Sik., 2003. "Country Survey XVIII: The two Koreas' defence economy". Jurnal Defense and Peace Economics Vol. 14(1)

Caverley, Jonathan D., 2007. "United States Hegemony and the New Economics of Defense." Journal of Security Studies, Vol. 16, No. 4 (Oktober-Desember 2007) 
Hall, Abigail R. dan Coyne, Christoper J., 2013. "The Political Economy of Drones.”Jurnal Defense and Peace Economics Vol. 25, Issue 5

Hartley, Keith dan Derek Braddon., 2014. "Collaborative Projects and the Number of Partner Nations. Jurnal Defense and Peace Economics Vol. 25, No. 6

Heo, Uk \& Sung Deuk Hahm, 2006. "Politics, Economics, and Defense Spending in South Korea”. Jurnal Armed Forces \& Society, Vol. 32 No. 4, Juli 2006.

Kaldor, Mary, 1986. "The Weapons Succesion Process". Jurnal World Politics, Volume 38, Issue 4.

Kim, Seung Keon, 2000. "The Political Economy of Defense Procurement and Acquisition: The Case of South Korean Ministry of Defense. Jurnal Global Economic Review Vol. 29, No. 2

Lindblad, J. Thomas, 2000. "Korean Investment in Indonesia: Survey and Appraisal. Jurnal Bulletin of Indonesian Economic Studies. Vol 36 No 1, April 2000.

Moon, C. \& Lee J., 2008. "The Revolution in Military Affairs and the Defence Industry in South Korea", Jurnal Security Challenges, Vol. 4, No. 4 (Summer).

Sebastian, Leonard C. \& Iis Gindarsah, 2013. "Assesing Military Reform in Indonesia". Jurnal Defense and Security Analysis Vol. 29, No. 4.

Tan, Andrew, 2011. "East Asia's Military Transformation: The Revolution in Military Affairs and its Problems". Jurnal Security Challenges, Vol. 7, No. 3 (Spring)

\section{Tesis}

Hartemink, Riane Rozemarjin, 2011. The Iron Triangle: Congress and Solidification of the Military-Industrial Complex between 19451974. Tesis Magister. Amsterdam: Universiteit Utrecht.

\section{Daring/Online}

Harian Terbit, 2015."Kerjasama Dengan Korsel Batal Sepihak Indonesia Rugi Ratusan Miliar", [online] dalam http://nasional.harianterbit.com/nasional/2015/05/13/28420/2 5/25/Kerjasama-Dengan-Korsel-Batal-Sepihak-Indonesia-RugiRatusan-Miliar, [diakses 20 Agustus 2015]

Kedutaan Besar Republik Korea untuk Republik Indonesia, 2015. "Sejarah Hubungan Diplomatik Korea Selatan-Indonesia", [online] dalam 
http://idn.mofa.go.kr/worldlanguage/asia/idn/bilateral/politik/ sejarah/index.jsp\#, [diakses 15 November 2015]

Kompas Nasional, 2011. "DPR: Kaji Ulang Kerja Sama Pesawat Tempur”, diunduh

dari http://nasional.kompas.com/read/2011/o1/11/11034158/DPR.K aji.Ulang.Kerja.Sama.Pesawat.Tempur, [diakses 30 Oktober 2015]

Korea Joong Daily, 2015. "US Denying Seoul key fighter jet technologies", [online] dalam http://koreajoongangdaily.joins.com/news/article/article.aspx?a id $=3009537$, [diakses 30 Oktober 2015]

Korea Times, 2015. "Lockheed Martin ready to commit to help KFX project", [online] dalam http://koreatimes.co.kr/www/news/nation/2013/o5/113_13564 2.html, [diakses 28 Oktober 2015]

Ministry of Foreign Affairs of Japan, 2006. "Joint Statement Between The Republic of Korea and The Republic of Indonesia”, [online]. dalam

http://www.mofa.go.kr/webmodule/htsboard/template/read/ko rboardread.jsp?typeID $=12 \&$ boardid $=8588 \&$ seqno $=305331$ [diakses 15 November 2015]

SIPRI, 2015. "Trends in World Military Expenditure". Stockholm International Peace Research Institute (SIPRI), diunduh dari http://books.sipri.org/product_info?c_product_id $=458 \#$ [diunduh 7 Oktober 2015]

Space Daily, 2015. "S. Korea opts for KAI-Lockheed Martin in $78 \mathrm{Bn}$ Fighter Deal”, [online] dalam http://www.spacedaily.com/reports/S_Korea_opts_for_ KAI-Lockheed_in_78_bn_fighter_deal_999.html, [diakses 22 November 2015]

Tempo, 2015. "Tarik Ulur Jet Tempur Korea-Indonesia”, [online] dalam http://nasional.tempo.co/read/news/2015/o9/21/078702377/fe ature-tarik-ulur-jet-tempur-korea-indonesia/2, [diakses 21 September 2015]

\section{Wawancara}

Anne Kusmiyati (Kepala Badan Penelitian dan Pengembangan Kementerian Pertahanan Republik Indonesia), 5 September 2015

Gita Amperiawan (Kepala Sub Direktorat Teknologi dan Industri Pertahanan, Kementerian Pertahanan), 17 November 2015

Jeoung Gi-young (Sekretaris I Kedutaan Besar Republik Korea Selatan untuk Indonesia), 11 September 2015

Marsdya TNI (Purn.) Eris Heryanto (Mantan Sekretaris Jenderal Kemhan), 4 Agustus 2015 